\title{
Implanon NXT embolisation into the pulmonary arterial tree
}

Maryam Shekarforoush, Shelley Chapman, Heather K Moriarty, Jim Koukounaras, Gerard S Goh, Warren Clements

\section{CASE}

A woman aged 26 years was referred to interventional radiology for removal of an impalpable contraceptive implant (Implanon NXT) device.

The device had been inserted three years prior by a general practitioner (GP), and the patient recalled that it was palpable immediately after insertion. The interventional radiology team did not have access to the GP's notes to confirm this. The patient noticed soon after the insertion that the implant became no longer palpable. The patient's body mass index was in the normal range at $21.3 \mathrm{~kg} / \mathrm{m}^{2}$ and had remained stable over the past three years. There was no trauma to the arm in this time.

While initially having complete cessation of menses as a resut of insertion of the device, two years post-insertion the patient had return of menses and wished to explore alternative contraceptive methods. At this time, the patient was referred to a gynaecologist. After contact with the gynaecologist, alternative oral contraception was arranged; however, it was decided that the Implanon NXT be left in place. As the patient recalls, the Implanon NXT was not palpable at the gynaecology outpatient consultation. The interventional radiology team did not have access to notes from this outpatient clinic.

The patient recalled that three years post-insertion, she presented to the same GP as she wished to have the Implanon
NXT removed, at which point she was referred to a gynaecology unit at a tertiary hospital for ultrasound-guided removal of the Implanon NXT.

Initial ultrasonography of the left arm to locate the impalpable Implanon NXT did not find the device. Given concerns that the device may have embolised, a chest radiograph was performed and, given suspicion for identification in the lung, computed tomography (CT) of the chest was arranged. This showed that the device had migrated through the venous system and was lodged in a third-order pulmonary artery in a longitudinal orientation (Figure 1A), with the distal end in the lung parenchyma (Figure 1B). There was no pulmonary infarction, consolidation, ground glass density to suggest haemorrhage or any other pulmonary complication (Figure 2).

Following identification of the device in the lung, the patient was referred to a dedicated interventional radiology
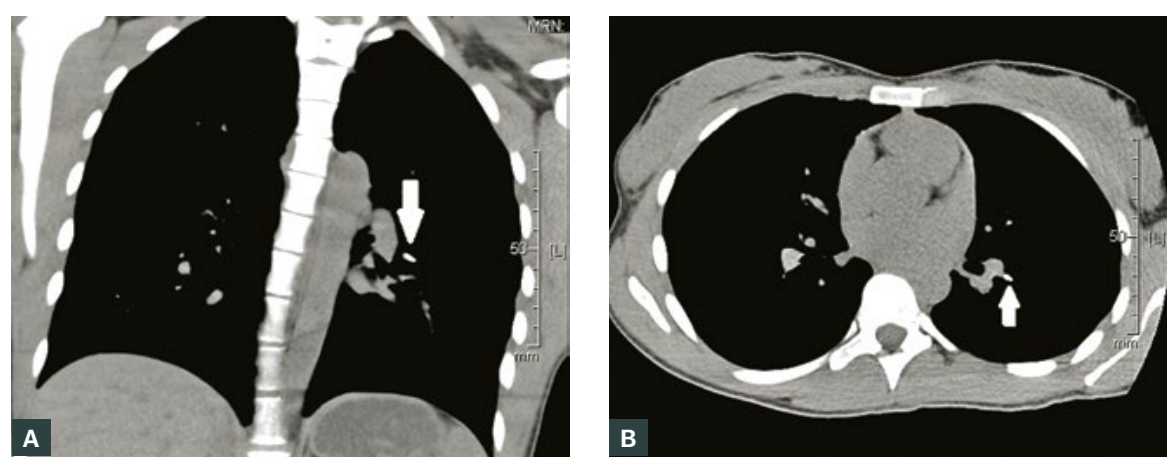

Figure 1. Non-contrast computed tomography lung reformats showing pulmonary embolisation of Implanon NXT device (arrow), with the proximal end in the pulmonary artery and the distal end within the lung parenchyma

A. Coronal view; B. Axial view outpatient consulting clinic for an opinion on removal of the device.

\section{QUESTION 1}

Where is the best location for Implanon NXT insertion in the body?

QUESTION 2

What are some complications of Implanon NXT insertion?

\section{QUESTION 3}

How is it most probable that the Implanon NXT device reached the lung?

\section{QUESTION 4}

What steps can be taken when a patient presents with an Implanon NXT device that is no longer palpable?

\section{ANSWER 1}

Implantable contraceptive devices such as the progestogen-only single-rod 


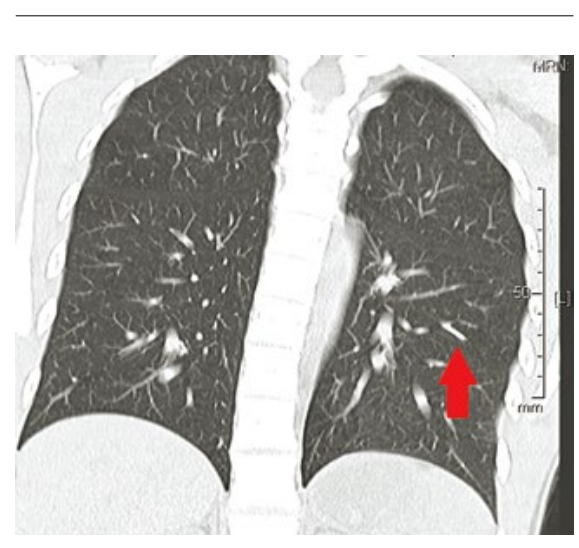

Figure 2. Coronal non-contrast computed tomography lung reformat showing embolised device (arrow) and normal lung distal to this

Implanon NXT are ideally placed into the subcutaneous tissue, subdermal on the inner side of the non-dominant upper arm. Manufacturer updates indicate that it is recommended to insert over the triceps area and to avoid insertion in the sulcus between the biceps and triceps, to avoid complications such as the one in this case. ${ }^{1}$

\section{ANSWER 2}

Complications that can arise from local trauma related to insertion include bruising, swelling, pain and itch, infection, formation of scar tissue, changes to sensation, numbness and expulsion.

Migration of an Implanon NXT device after insertion is uncommon; $;^{2,3}$ however, local movement in the arm after insertion has been described before the device is fixed with scar tissue. This local movement is generally $<2 \mathrm{~cm}$.

\section{ANSWER 3}

After successful insertion, the device becomes fixed locally with fibrous scar tissue within the first three months and is unlikely to move any further. It is most likely that the device embolised soon after insertion via passage through an arm vein (likely the basilic vein) and had been lodged in the pulmonary system since that time.

\section{ANSWER 4}

Given that most patients using Implanon NXT are young, it is recommended to commence with localised imaging including ultrasonography and/or radiography of the arm as this will identify the device in almost all cases. If the device is not located, a chest radiograph is recommended as a next step, and a CT scan could be considered if the radiograph is abnormal and/or after discussion with a radiologist.

There have been case reports of endovascular migration, ${ }^{4}$ and in 2014 , the first known case of pulmonary embolisation was reported. ${ }^{5} \mathrm{~A}$ further case that described endovascular retrieval was reported in 2015 for a patient in whom the device migrated to the right main pulmonary artery. ${ }^{6}$

Endovascular embolisation of an Implanon NXT device remains a very rare complication in current literature and is limited to case reports. ${ }^{7-9}$

\section{CASE CONTINUED}

The patient was asymptomatic of the embolised Implanon NXT. Examination and vital observations were normal.

After multidisciplinary discussion between the cardiothoracic surgery and interventional radiology units, it was decided that it was not necessary to remove the device given its location in the lung, that it was not currently active (given the return of menses) and the patient was asymptomatic.

\section{Key points}

- Migration of Implanon NXT remains an uncommon complication.

- Endovascular migration is a rare but serious complication that requires specialist input for potential operative or endovascular retrieval by an interventional radiologist.

- For any impalpable device, it is recommended that the clinician considers imaging to show its location.

\section{Authors}

Maryam Shekarforoush BMedSc, MBBS, Intern Department of Radiology, Alfred Hospital, Vic Shelley Chapman MB BChir MA (Hons), FRCR, Interventional Radiology Fellow, Department of Radiology, Alfred Hospital, Vic
Heather K Moriarty MB, BCh, BAO, MMedSc, MRCPI, FFRRCSI, Interventional Radiology Fellow, Department of Radiology, Alfred Hospital, Vic; Adjunct Lecturer, Department of Surgery, Monash University, Vic

Jim Koukounaras BMBS, FRANZCR, EBIR, Consultant Interventional Radiologist, Department of Radiology, Alfred Hospital, Vic; Department of Surgery, Monash University, Vic

Gerard S Goh MBBS, FRANZCR, EBIR, Consultant Interventional Radiologist, Department of Radiology, Alfred Hospital, Vic; Department of Surgery, Monash University, Vic

Warren Clements BBiomedSc (Hons), MBBS, FRANZCR, EBIR, Consultant Interventional Radiologist, Department of Radiology, Alfred Hospital, Vic; Department of Surgery, Monash University, Vic.w.clements@alfred.org.au

Competing interests: None.

Funding: None.

Provenance and peer review: Not commissioned, externally peer reviewed.

\section{References}

1. Pearson S, Stewart M, Bateson D. Implanon NXT: Expert tips for best-practice insertion and removal. Aust Fam Physician 2017;46(3):104-08.

2. Ismail H, Mansour D, Singh M. Migration of Implanon NXT. J Fam Plann Reprod Health Care 2006;32(3):157-59. doi: $10.1783 / 147118906777888413$.

3. Medicines and Healthcare products Regulatory Agency. Nexplanon (etonogestrel) contraceptive implants: Reports of device in vasculature and lung. London, UK: Gov.UK, 2016. Available at www.gov.uk/drug-safety-update/ nexplanon-etonogestrel-contraceptiveimplants-reports-of-device-in-vasculatureand-lung\#reports-and-potential-risk-factors [Accessed 26 March 2020].

4. Barlow-Evans R, Jaffer K, Balogun M. Migration of a Nexplanon contraceptive implant to the pulmonary artery. BMJ Case Rep 2017;2017:bcr2017-219259. doi: 10.1136/bcr-2017-219259.

5. Patel A, Shetty D, Hollings N, Dodds N. Contraceptive implant embolism into the pulmonary artery. Ann Thorac Surg 2014;97(4):1452. doi: 10.1016/j. athoracsur.2013.09.029.

6. Heudes P-M, Querat VL, Darnis E, Defrance C, Douane F, Frampas E. Migration of a contraceptive subcutaneous device into the pulmonary artery. Report of a case. Case Rep Womens Health 2015;8:6-8. doi: 10.1016/j.crwh.2015.09.002.

7. Akhtar MM, Bhan A, Lim ZY, et al. Percutaneous extraction of an embolized progesterone contraceptive implant from the pulmonary artery. Open Access J Contracept 2018;9:57-61. doi: 10.2147/OAJC.S165827.

8. Chung M, Loudill C, Wieler M, Farnam J, Ahn SH. Endovascular retrieval of Nexplanon from the distal pulmonary artery. J Vasc Interv Radiol 2017;28(3):466-67. doi: 10.1016/j.jvir.2016.09.011.

9. Rowlands S, Mansour D, Walling M. Intravascular migration of contraceptive implants: Two more cases. Contraception 2017:95(2):211-14. doi: 10.1016/j.contraception.2016.07.015. 